\title{
DOI 10.26886/2520-7474.6(44)2020.11
}

UDC: $37.09: 378$

CASE METHOD IN THE CREATIVE POTENTIAL DEVELOPMENT OF HEADS OF VOCATIONAL INSTITUTIONS

\section{N. Golia}

https://orcid.org//0000-0002-5745-8392

e-mail:natali_golia@ukr.net

Khmelnytskyi Higher Vocational School, Ukraine, Khmelnytskyi

The article deals with the essence of the case method, its purposes and objectives, the place and importance of the method in the creative potential development of the managers of vocational institutions, the characteristics of the case method, its principles, its structure, its influence on the formation of the quality characteristics of the specialist; the technology of preparing the case and the specifics of its application in the training of the heads of vocational institutions in the system of postgraduate pedagogical education have been introduced.

Key words: case method, analysis, situation, innovation, creativity; creative activity.

Problem statement. The dynamic nature of current socio-economic conditions makes it increasingly necessary to establish the personality of the head of a vocational institution and the basic principles of his/her activity. This applies both to the level of professional competence and to the development of personal qualities that make it possible to carry out managerial tasks efficiently and effectively. First and foremost is the development and enrichment of the creative potential of managers in the process of developing their professional career.

This problem is of particular importance in the present circumstances, since the objective high level of professionalism of the heads of vocational 
institutions can be ensured only through continuous vocational training and improvement in the postgraduate pedagogical education.

The development of the creative potential of heads of vocational institutions today must not only be practical-oriented, but it must be enriched by innovative technologies and teaching methods also. As it is known, «innovation» is the creation and application of something new. Innovations in the system of teaching methods are particularly relevant, in a direction that transforms learning methods into self-learning methods, directing leaders not so much towards the acquisition of knowledge as towards the development of the cognitive potential of the individual, improvement of creative abilities and development of such methods, which influence the internal structure of the personality - motivation, values and orientation, interests and needs. In view of this, one of the most effective methods of developing the creative potential of managers of vocational institutions in postgraduate teacher training is the case method.

Analysis of recent studies and publications. In general the problems of creativity are the focus of scientific attention of many researchers. Philosophical aspects of creativity are considered in the works of M. Bakhtin, V. Bibler, V. Vernadskyi, B. Kedrov, O. Losiev, M. Yaroshevskyi. The problem of managerial creativity as a subject of scientific analysis is considered in three directions: general psychological approach in research of creativity (B. Ananiev, V. Bible, A. Brushlinskyi, Ya.Ponomaryov, V.Romanets, S. Rubinstein, O. Tykhomyrov) the interrelation of creativity with such phenomena as creativity to work, creative thinking, creative potential, creative abilities (E. de Bono, J.R. Guilford, Z. Kalmykova, A. Kovalenko, I. Manoha, A. Maslow, V. Matiushkin, V. Molyako) and the mutual influence of creativity and professional activity of the head, his/her professionalism and professional skills (S. Hilmanov, G. Davydova, A. Derkach, I. Semenov, S. Stepanov, 

A. Esaulov, T. Sorochan, V. Oliynik, L. Kalinina, H. Timoshko, V.Ryabova, O. Snisarenko, L. Karamushka).

Today considerable experience has been accumulated in the theory and practice of vocational education, covering the problems of using interactive learning technologies in the educational process.

The term «case-study» was first used in the early 20th century. The case method was first used in the Harvard Business School training process in 1921. The first case scenarios for business students were developed in Harvard. In Western Europe, the case has been in active use since the 1960s. Among the foreign scientists who have been actively working on the use of the cases are M. Leedere, E. Montera, M. Norphi. The problem of using the case method in teaching different disciplines in the education system was addressed by Yu.Surmin [9], O. Sydorenko [8], P.Sheremeta, V.Chub, G.Kanishenko [10]; S.Sysoeva [6], etc. The case nethod is actively used abroad in the training process: in the USA (J.Maan, D.Krukshank, G.Sykes, T.Berdt et al.), England (M.Reichelt, R.Pring), Australia (A.Watson).

However, the problem of using the case method in the process of developing the creative potential of the heads of vocational institutions in the system of postgraduate education remains underdeveloped. The purpose of the article is to justify the need to use the case method in developing the creative potential of the heads of vocational institutions in the system of postgraduate pedagogical education.

Presentation of the main material. One of the main tasks for the development of the modern vocational system in Ukraine is to ensure the professional development and improvement of the heads of vocational institutions throughout their professional life. Taking into account the peculiarities of professional management activities, the content and 
substance are creative activities, it is important to emphasize that the development of the personality of a head of institution is a prerequisite and an indispensable component of his professionalism.

Our attention to the problem of the creative potential development of the head of a vocational institution is primarily due to the fact that the elements of management as well as self-management inherent in any professional activity related to interpersonal interaction. On the other hand, the creative potential development of the education manager is one of the most important problems in the context of management, which is impossible without collective creativity; innovative management, where creativity and initiative occupy a prominent place in management practice; where competition will not succeed without a constant creative search, but where the concept defines the personality, the importance of which requires a proper assessment of the relevance and irreplaceability of the modern education system.

Creativity plays a significant role in the activities of the heads of vocational institutions, prompting them to constantly search for and create new methods of management, overcoming stereotypes and patterns. In the process of creative activity, the establishment of vocational education is developing, and new structures, new knowledge and new ways of working are emerging.

The creative potential of the heads of vocational institutions is dynamic and constantly undergoing transformation and is part of the collective professional culture of the specialist. It is therefore legitimate to speak of its development in the educational system. It can be considered that the creative potential of the heads as professionals is also developed in the process of training in higher education institutions. In postgraduate education, however, it develops in different directions. 
The current postgraduate pedagogical education system is an integral social institution with its structural elements and lines of action (socioeconomic, psychological, pedagogical, theoretical, practical, methodological and managerial) components of an organic system of continuing education, The further development of which is possible, provided that it is linked to other components of the educational system; the system of continuing education and retraining of graduates; the form of adult education based on their individual needs for specific knowledge, skills, personal and professional development.

The system of postgraduate pedagogical education plays a special role in the process of developing the creative potential of heads of vocational institutions:

- In postgraduate education, specialists who already have a higher education in the teaching profession are taught; their combined professional culture includes the necessary basic knowledge, skills, professional and personal qualities; based on enriched professional experience, updated and enriched knowledge, skills and abilities, the creativity of the manager is further mainstreamed from a priori-potential to an effective-potential position (providing creative professional activities);

- In the postgraduate pedagogical education system specialists with professional experience are trained; in the further development and enrichment of vocational training. The pedagogical experience reinvigorates the potential creative abilities and capabilities of the leaders, that is, the professional experience of the heads of vocational institutions also plays a role as an incentive, and is a condition for revitalizing and developing their creative potential;

- In the context of postgraduate pedagogical education androgynous principles and teaching models are being implemented; conditions are being created for the development of the creative potential of heads of 
vocational institutions;

- The system of postgraduate pedagogical education is characterized by an innovative direction in which the innovative activities of the heads of vocational institutions and their creative potential are linked; the innovative direction of postgraduate pedagogical education includes the process of effective development of creative potential of heads by means of modern learning technologies.

Modern teaching technologies are a qualitatively new set of forms, methods and means of teaching, education and management, bringing about significant changes in the outcome of the pedagogical process. Modern training technologies in the system of advanced training of heads are: e-textbook, coaching, network technology, case technology and others.

Consider the case-technology method in more detail. First of all we will find out what is invested in the essence of the concept of "case» and «case method». According to the classical definition of the case method (case method, case-study, case situation method) is a learning method based on solving specific problem situations.

From the methodological point of view the case is a specially prepared educational material containing a structured description of the situation, taken from actual practice. The briefcases immerse themselves in a problem, force them to find a solution to a particular problem.

O. Sidorenko defines the case as "a real management problem or situation that may arise for the head of an enterprise or an organization, as defined by an administrative unit, and usually requires a management decision" [7].

The essence of the case method consists in the autonomous cognitive activity of heads in an artificially created professional environment, which makes it possible to combine theoretical training with practical skills, 
necessary for professional creativity. The heads are asked to reflect on the real management situation, the description of which reflects the problem, takes place in a professional activity and the need to address it. In the process of solving a problem situation, the managers will update the set of knowledge acquired in the past.

In terms of methodology, the case method has much in common with problematic learning methods. However, as the [3], [5], [7] researchers noted the case method have its own peculiarities, namely: the existence of a problem hidden under a problem situation; the problem in the case method is more specific, practical, as opposed to theoretical problems, which are considered in the process of problem learning; the case method refers to innovative methods, although it has a close connection with traditional pedagogical methods, it is interactive, collaborative and business-oriented, as the work takes place in groups. It is possible to use the method in any subject, but it is advantageous to take courses or topics whose truth is pluralistic, that is, it is not straightforward, but allows for several competitive ideas, concepts and the like. At the same time, the task of the teacher of the postgraduate educational institute is to activate the heads in search of different truths and approaches and help them to orient themselves in the problem field. Learning by the case method is not about learning, but about making of the knowledge. The result of the method is not only knowledge, but also skills, as well as the development of a system of values, professional positions, attitudes and a professional world.

Looking at the essence of case-study, O. Dolgorukov highlights the following features of it, namely: the existence of a model of a socioeconomic system whose state is under consideration at a certain point in time; collective development of solutions; multi-alternative solutions; a fundamental lack of a single solution; a single goal in the decision-making 
process; a system of collective assessment of activities; the presence of managed emotional tension of the heads [2].

The cases are of a clearly defined nature and purpose. As a rule, they relate to real-life situations in which practical solutions are necessary. The best solution to the problem is determined by analysing the situation and through the assessment of the produced alternatives. Situation analysis involves different types of analytical work. The researchers believe that the richer arsenal of analytical methods defines the more successful the process of using the case method [7, 30-32].

It should be noted that the training of the heads of vocational institutions in analytical methods contributes to the development of the necessary qualities for creative activity. Thus, the possession of problem analysis teaches certain aspects of social sensitivity, the sense of problems that need to be addressed. Systems analysis forms a holistic view of processes. Praxeological analysis develops pragmatism of activity and thinking, influences performance. Predictive analysis creates a desire for continuous logical reflection and anticipates the possible consequences of decisions that can be expected in the future. A cause-and-effect analysis reveals the causes that led to this situation and the implications of its deployment. Axeological analysis implies the construction of a system of assessments of the situation, its components, conditions, consequences, actors from the standpoint of a value system [7].

It is important to highlight that a particular situation does not involve the full range of analytical methods. It may be limited to only some of the listed items.

The purpose of the case method is to enhance the educational and cognitive activities of managers, acquire the skills of analysis and find the 
best solution to the situation. Case activates the activities of managers, develops their analytical and communicative abilities.

The case method, as a form of educational process activation, helps to build meta-competence and successfully accomplish the following tasks:

- To develop the skills and techniques of comprehensive analysis of the situation in the field of professional activity, to help solve similar problems that arise in practical activities;

- To develop problem-solving skills, which are produced in the process of simulating one's own actions in a problem situation, which allows managers to test one's own beliefs, theoretical knowledge and prejudices;

- Rapid decision-making - «here and now»;

- To acquire skills in recruitment, that is, to express one's point of view clearly and verbally or in writing;

- To develop the ability to present, that is, to convincingly substantiate and defend one's point of view; to develop the skills to constructively critically evaluate the views of others;

- Learning from practical experience to benefit from their mistakes as well as those of others around them [5].

In order to realize the internal potential of the case method in the process of developing the creative potential of vocational educational heads in postgraduate pedagogical education, the following didactic principles should be observed: individualized approach to each supervisor, taking into account his needs and style of learning, maximising information prior to the start of the training; maximising freedom of learning (choice of teacher, subject, form of training, type of tasks and manner of their execution); provision of sufficient visual material to supervisors; no downloading of large volumes of theoretical material; focus on substantive provisions only; possibility of active collaboration between trainer and trainee; development of managerial self-management skills, knowledge management skills; focus 
on developing managerial strengths $[6,210]$. The system of defined interlocking principles should guide pedagogical activities at all stages of the case method implementation.

The functional capabilities of the case method have an extremely wide range - training, learning, analysis, research, systematization, forecasting [6]. All functions are organically linked and represent system integrity, although certain activities may be dominated by some of them.

For a teacher of a postgraduate educational institution, it is important that the nature of the dominant function is consistent with the purposes and objectives of the use of the case and that the core is educational and developmental [3].

In the methodological context the case method is a complex system in which other methods of learning are integrated: modeling, systems analysis, problem method, experiment, description method, classification method, play methods, brainstorming [7, c. 57]; discussion, trial and error method, collective notebook method, solution of creative problems in «Pgroups», method of synectic analysis, method of morphological analysis, method of focal objects, control questions, method of seven-fold search, method of inversion (reverse motion)nominal group technique, Delphi method and others [3, 87-102].

The application of traditional general educational, research, innovation and heuristic methods will contribute to the effective implementation of problem analysis and creative situations.

It should be noted that the use of the case method contributes to the development of competencies required by heads for creative professional activities, such as production and decision-making skills; and learning ability; systemic thinking; autonomy and initiative; willingness to change and flexibility; business and business orientation; ability to work with information; 
tenacity and commitment; communicative ability; ability to interact interpersonally; problem thinking; design [7, 60].

An important feature of the case method is the preparation of the teacher of postgraduate pedagogical educational institution for its use, which requires him/her to constantly develop and improve.

The first step is to prepare the case. Case is a special complex containing a description of the situation, a problem statement, questions to be addressed by students, materials on educational information, a list of sources of information.

There's no consensus on the structure of the case. For example, Yu. Surmin singles out three components of the case: the story, which is the sum of actions and events, discloses the contents of the case; the information, which contains the information needed for the case; the methodological part, which explains the place of this case in the course of the subject and formulates the tasks of analyzing the case $[3,168]$. When you start developing a case, you have to understand all the technological stages. It is based on understanding the multifaceted sources for solving the problem, developing a situation story and creating a case.

Innovative cases contain innovations. They are usually understood as a new means of meeting a need more effectively. Innovation is an essential part of society and modern education, especially when it is being reformed. Their emergence and development give rise to a large number of multifaceted problems and they are analysed in the cases. Science (analysis, new paradigms, concepts, case-based approaches) and education are the main sources for the creative potential development (new goals and tasks of teaching and upbringing, methods of teaching and upbringing, integrated in the case method).

Experience has shown that cases should be designed and implemented in the educational process for the establishment of 
postgraduate pedagogical education, taking into account a number of principles to ensure their effective use, namely: the case should be consistent with the aims of the training; the case should be as close as possible to the actual professional activity; the task should include different ways of finding solutions; the case may differ in the level of generality, the quantity of information provided, the complexity of the problem; the case file should not be outdated but should be updated in parallel with changes in actual practice.

In the theory of application of case-technologies there are three main variants of use of method: diagnosis of a problem and elaboration of methods of solving it; forecasting of a situation (the main task development of a project in the form of a forecast of «development of a vocational institution» etc.) evaluation of situations with proposed solutions (both the problem and its solution can be described in the instruction) [5].

The following are the main stages in the construction of the case:

1) to define the purpose of the case;

2) to identify a specific real situation in accordance with the relevant objective;

3) to undertake preliminary work on the sources of information for the case;

4) to collect data for the case, various sources, including contacts with the organization described in the case;

5) to prepare a first version of the case. This stage includes the layout, presentation form (video, print, etc.);

6) to discuss the case with the widest possible audience and to obtain expert opinion from colleagues before it is validated. Based on this assessment, necessary changes and improvements can be made to the case

7) to provide guidance on the case usage. To develop tasks and 
possible questions for discussion and presentation of the case, describe the intended actions at the time of discussion of the case [1].

The implementation of the case method in the process of creative potential development in the postgraduate pedagogical education system includes several stages: acquainting the heads of vocational institutions with the text of the case, organizing discussion of the case in subgroups, discussion management, discussion evaluations, case by case summingup, performing creative independent task on the subject of the case [3].

Thus, the activity of the teacher the of postgraduate pedagogical educational institution when using the case method contains two phases. The first is the complex and creative work of creating the case and the questions to analyse it. It is carried out outside the audience and involves the research and methodological activities of the teacher. The second phase includes the activities of the teacher in the audience, where he makes introductory and closing remarks, organizes small groups and discussions, supports the business attitude of the audience, evaluates the contributions of the participants to the analysis of the situation [4].

As noted by domestic researchers the application of the case method on the one hand stimulates individual activity of managers in the system of postgraduate pedagogical education, forms a positive motivation for learning, reduces the array of "passive» and unsure managers, provide high-efficiency training and development of managers, develop certain personal qualities and competencies, and on the other hand it enable the teacher to self-improvement [8].

In such circumstances, the postgraduate pedagogical education system takes on a fundamentally different status, namely: it provides knowledge that sets standards in future practice, it establish a platform and forecast the professional self-development of the heads of vocational institutions in an appropriate perspective. The process of bringing about 
innovative changes in the educational process of postgraduate pedagogical educational institutions is helping to create a new model of professionalism, the essence of which is to motivate the level of creativity of managers.

Conclusions. Thus, considering the problem of developing the creative potential of heads of vocational institutions we believe that it is important to design such forms and methods of study in the system of postgraduate pedagogical education, that would better balance the reproductive and productive components of training, promoting the reconciliation of the personal capacities of managers with the requirements of the professional development process. The study found that the pedagogical potential of the case method is much greater than that of traditional teaching methods. The use of the case method in the process of developing the creative potential of the heads of vocational institutions in the system of postgraduate pedagogical education is particularly significant, because it requires heads to be as close as possible to real professional situations and to make appropriate decisions. Through the case-study method, heads have the opportunity to study complex professional issues, develop the ability to highlight problems, analyse and develop action programs, which will enable them to act in a balanced manner in the future.

At the same time, modern postgraduate education requires a more indepth study of the theoretical underpinnings of the case method, as well as the characteristics of its optimal practical application in the various components of the pedagogical process.

\section{References:}

1. Grebenkova G. Case method in vocational training URL: http://www.nmc.od.ua/wpcontent/uploads/2011/01/

2. Dolgorukov A. Case-study method as a modern technology of vocational training

URL: 
http://www.vshu.ru/lections.php?tab_id=3\&a=info\&id=2600

3. Innovative Learning Technologies in the Activity of Educational Engineer (2013): Training Manual for Educational Engineer: at 2 a.m. Edited by A. E.Kovalenko, L. V. Stefan. Kharkiv, Izd-vo LLC «Digital Printing House 1», 2013. Series «Theoretical Bases». 195.

4. Ozerova L. (2012) Case studies method as an effective form of instruction of students of geographical specialities. Scientific notes of V.I. Vernadsky Taurik National University. Series «Geography». Vol. 25 (64). 87-96.

5. Panfilova A. (2009) Innovative pedagogical technologies : Active teaching. Moscow, Publishing Center «Academy».

6. Sysoieva S.(2011) Interactive technologies for adult education: teaching aid. APS of Ukraine, Institution of pedagogical education and adult education. Kyiv, ID «EKMO».

7. Situational Teaching Methodology: Theory and Practice (2001). Kyiv, Centre for Innovation and Development.

8. Surmin Yu., Sydorenko A., Loboda V., Furda A., I. Katejnyak, Kesi Meer (2002). Situational analysis, or Anatomy of the case method. Edited by Prof. Surmina Yu. P. Kyiv, Centre for Innovation and Development.

9. Surmin Yu. (2001) End of the era of «diligent men». Case method as a means of qualitative updating of Ukrainian education. Synergia. Vol. 2-3. 27-33.

10. Sheremeta P., Kanishchenko L. (1999) Case method: from the experience of teaching in the Ukrainian business school. Edited by $A$. Sidorenko. Moscow, Centre for Innovation and Development. 
cited, in accordance with accepted academic practice. No use, distribution or reproduction is permitted which does not comply with these terms. 